\title{
MODELAMIENTO MOLECULAR DE LA CRUZIOSEPTINA CC-16 EXTRAÍDA DE LA RANA Cruziohyla calcarifer
}

\author{
MOLECULAR MODELING OF CRUZIOSEPTIN CC-16 \\ EXTRACTED FROM THE FROG Cruziohyla calcarifer
}

\section{Felipe Morales P. ${ }^{1}$, Sebastián Cuesta H. ${ }^{1}$, Carolina Proaño-Bolaños ${ }^{2,3}$ \& Lorena Meneses O. ${ }^{1 *}$}

Recibido: 30 de abril 2021 / Aceptado: 1 de julio 2021 10.26807/ia.v9i2.215

Palabras clave: Acoplamiento molecular, Cruzioseptinas, Cruziohyla calcarifer, modelamiento molecular, péptidos antimicrobianos.

Keywords: Antimicrobial peptides, antimicrobial peptides, Cruzioseptins, Cruziohyla calcarifer, Molecular docking.

\section{RESUMEN}

El creciente desarrollo de resistencia a antibióticos por parte de mundo microbiano es un problema cada vez mayor y en respuesta nuevas moléculas con

1 Pontificia Universidad Católica del Ecuador, Facultad de Ciencias Exactas y Naturales, Escuela de Ciencias Químicas, Laboratorio de Química Computacional, Quito, Ecuador (ffmmjjpp@ @otmail.es; sebastian_cuesta@yahoo.com; *correspondencia: Immeneses@puce.edu.ec)

2 Universidad Regional Amazónica IKIAM, Grupo de Descubrimiento de Biomoléculas, Laboratorio de Biología Molecular y Bioquímica, Tena, Ecuador (carolina.proano@ikiam.edu.ec)

3 Queen's University Belfast, School of Pharmacy, Natural Drug Discovery Group, Belfast, UK (carolina.proano@ikiam.edu.ec) 
potencial antimicrobiano están siendo estudiadas, entre ellas los péptidos antimicrobianos como las Cruzioseptinas. Este trabajo presenta un estudio computacional preliminar de la Cruzioseptina CC-16 extraída del exudado de la piel de la rana Cruziohyla calcarifer. Con base en la secuencia de aminoácidos del péptido se llevaron a cabo diferentes estudios computacionales, entre ellos, la predicción de las propiedades fisicoquímicas y la estructura secundaria. Además de esto se efectuó el acoplamiento molecular de la Cruzioseptina CC-16 con diferentes enzimas de importancia biológica para microrganismos como Escherechia coli, Staphylococcus aureus y Candida albicans, y con moléculas presentes en la membrana celular bacteriana. Los resultados mostraron que la Cruzioseptina CC-16 es un péptido de 23 residuos de largo con una conformación alfa helicoidal predominante, un punto isoeléctrico de 10,73, una carga de +3 de carácter básica y una carga neta a $\mathrm{pH} 7$ de $+3,1$, además de tener más del 50 \% de su estructura conformada por aminoácidos hidrofóbicos, clasificando como un péptido antimicrobiano catiónico. Los estudios preliminares de acoplamiento molecular muestran que un mecanismo de acción basado en inhibición enzimática no es posible, debido principalmente al tamaño del péptido, mientras que un mecanismo con base en un ataque concentrado en la membrana microbiana puede ser viable, debido a las interacciones electrostáticas de la Cruzioseptina CC-16 con diferentes componentes de la membrana.

\section{ABSTRACT}

The increasing development of resistance to antibiotics by the microbial world is a growing problem and in response new molecules with antimicrobial potential are being studied, among them antimicrobial peptides such as Cruzioseptins. This work presents a preliminary computational study of Cruzioseptin CC-16 extracted from exudate from the skin of the frog Cruziohyla calcarifer. Based on the amino acid sequence of the peptide, different computational studies were carried out, including the prediction of its physicochemical properties and its secondary structure. In addition to this, a molecular docking study of Cruzioseptin CC-16 was carried out with different enzymes of biological importance for microorganisms such as Escherichia coli, Staphylococcus aureus 
and Candida albicans, and with molecules present in the bacterial cell membrane. The results showed that Cruzioseptin CC-16 is a 23 residues long peptide with a predominant alpha helical conformation, an isoelectric point of 10.73, a basic charge of +3 and a net charge at $\mathrm{pH} 7$ of +3.1 , in addition of having more than $50 \%$ of its structure made up of hydrophobic amino acids, fitting the definition of a cationic antimicrobial peptide. Preliminary molecular docking studies show that a mechanism of action based on enzyme inhibition is not possible mainly due to the size of the peptide, while a mechanism based on a concentrated attack on the microbial membrane may be viable due to the electrostatic interactions of the Cruizoseptin CC-16 with different components of the membrane.

\section{INTRODUCCIÓN}

La constante evolución de los seres vivos ha significado el desarrollo de nuevos mecanismos de defensa por parte de estos para perpetuar su existencia en este planeta (Demori et al., 2019; Martinez, 2014; Rhouma et al., 2016; Roca et al., 2015; Walsh \& Wencewicz, 2014). Los microorganismos patógenos no se han quedado atrás, y cada día desarrollan una mayor resistencia contra los antibióticos utilizados en su contra, Ilegando a tal punto que las bacterias multirresistentes se han convertido en un problema global de salud (Candido et al., 2019; Martinez, 2014; Pe- ters et al., 2010; Roca et al., 2015; Walsh \& Wencewicz, 2014). En respuesta, la comunidad científica está poniendo grandes esfuerzos en la búsqueda y desarrollo de nuevos medicamentos mucho más potentes y eficaces, pero también menos peligrosos para el ser humano (Bastos et al., 2018; Cui et al., 2017; Peters et al., 2010; Walsh \& Wencewicz, 2014).

El desarrollo de nuevos antibióticos actualmente está centrado en dos líneas de investigación paralelas, la identificación en la naturaleza de 
moléculas con potencial antimicrobiano y el desarrollo de moléculas sintéticas con capacidad antibiótica (Haney et al., 2017; Roca et al., 2015; Walsh \& Wencewicz, 2014). Uno de los grupos de moléculas de origen natural que está Ilamando la atención debido a su constante presencia en el sistema de inmunidad innata de varios seres vivos son los péptidos antimicrobianos o AMPs por sus siglas en inglés (Ciumac et al., 2019; Haney et al., 2017; Peters et al., 2010).

Los AMPs son moléculas pequeñas de carácter anfipático con carga positiva de entre $+2 y+13$, constituidas por una cadena de entre seis y cien aminoácidos (Haney et al., 2017; Kumar et al., 2018; Latendorf et al., 2019). Con base en su estructura secundaria, los AMPs pueden ser clasificados en cuatro grades grupos, hoja- $\beta$, hélice- $\alpha$, bucle y péptidos extendidos. Su estructura secundaria suele presentarse de manera estable en un medio predominante de fosfolípidos y tienden a perder su conformación en medios acuosos (Ciumac et al., 2019; Haney et al., 2017; Hoagland et al., 2001; Peters et al., 2010; Rydberg et al., 2012; Walsh \& Wen- cewicz, 2014). La gran mayoría de estas moléculas son de carácter catiónico con más del 50 \% de los aminoácidos que los conforman de carácter hidrofóbico, además de poseer al menos dos aminoácidos básicos, como la lisina y la histidina, que aportan con cargas positivas extras al péptido (Ciumac et al., 2019, 2019; Kim \& Jin, 2019; Latendorf et al., 2019; Proaño-Bolaños, 2016).

Se han reportado más de 5000 AMPs con actividad contra diferentes organismos, mostrándose efectivos ante bacterias, hongos, virus, parásitos e incluso células cancerígenas (Bechinger \& Gorr, 2017; Ciumac et al., 2019; Latendorf et al., 2019). Los mecanismos de acción por los cuales los AMPs trabajan aún se encuentran bajo estudio, pero se ha llegado a describir las posibles formas en las que estas moléculas trabajan. Cabe recalcar que la función in vivo de varios AMPs no ha sido determinada, pues han mostrado cumplir diferentes funciones más allá de la de la protección contra organismos potencialmente peligrosos (Ciumac et al., 2019; Gorr \& Abdolhosseini, 2011; Kumar et al., 2018; Kwon et al., 2019). 
Los mecanismos de acción de los AMPs se pueden dividir en dos grandes grupos, la modulación inmunológica y la muerte directa. La modulación inmunológica se refiere a la capacidad de los péptidos para causar respuestas inmunes como la activación y conglomeración de glóbulos blancos, la estimulación de la angiogénesis y la reducción de la inflamación, lo que a la larga provocará la muerte de células patógenas (Feng et al. 2020; Gorr y Abdolhosseini 2011; Kumar et al. 2018). Por otro lado, los mecanismos por muerte directa se refieren a la interacción del péptido con diferentes moléculas presentes en la zona exterior o interior de la célula bacteriana (como enzimas y proteínas), el ataque y apertura de la bicapa lipídica bacteriana, y la disrupción de los enlaces entre la membrana y diferentes maquinarias moleculares (Bechinger \& Gorr, 2017; Ciemny et al., 2018; Ciumac et al., 2019; Kumar et al., 2018; Li et al., 2017; Rudi et al., 2010; Yasir et al., 2019).

La capa exterior de las bacterias Gram positivas y Gram negativas están compuestas principalmente por ácidos teicoicos y lipopolisacáridos, los cuales tienen una carga neta ne- gativa, convirtiéndolos en blancos para los AMPs catiónicos, debido a la atracción electrostática. A diferencia de las membranas bacterianas, las membranas animales se conforman por fosfolípidos iónicos híbridos tales como la fosfatidilcolina, la esfingomielina y otros componentes neutros como el colesterol, siendo poco atractivas para los AMPs catiónicos (Bechinger \& Gorr, 2017; Ciumac et al., 2019; $\mathrm{H}$ et al., 2019; Kumar et al., 2018; Li et al., 2017).

Existen varias fuentes de AMPs en la naturaleza, entre ellas se encuentra la piel de los anfibios. Las secreciones de las glándulas granulares de estos animales han demostrado ser una mezcla compleja de varias moléculas bioactivas, que resultan de una adaptación evolutiva debido a la exposición de estos animales a ambientes hostiles donde abundan los microorganismos patógenos (Conlon et al., 2019; Demori et al., 2019; I et al., 2018; Mingqiang et al., 2018). Estas secreciones se encuentran compuestas principalmente por alcaloides, diversas moléculas antioxidantes, péptidos, diferentes ácidos nucleicos, esteroides y una gran variedad de proteínas. 
Se han encontrado ya más de 100 familias de AMPs en más de 165 especies y 26 géneros, pero aún existen ciertos géneros que se mantienen en el anonimato, como el género Cruziohyla donde sobresale la Cruziohyla calcarifer, localizada desde el caribe hondureño hasta el noreste del Ecuador (I et al., 2018; Mingqiang et al., 2018; Proaño-Bolaños et al., 2019). Esta rana posee una gran proximidad taxonómica con la familia Agalychnis, bien conocida por su piel rica en péptidos bioactivos. Dentro de la piel de Cruziohyla calcarifer, se ha encontrado una nueva familia de péptidos con grandes propiedades antimicrobianas, las Cruzioseptinas (Lewin et al., 2017; Proaño-Bolaños, 2016).

Las Cruzioseptinas han sido recientemente descubiertas y han demos- trado un gran poder antimicrobiano, sin embargo, existen pocas investigaciones dedicadas a comprender en profundidad su accionar contra los microorganismos patógenos, generando una creciente necesidad de estudiarlas (Proaño-Bolaños, 2016). Este trabajo tiene como objetivo aplicar técnicas computacionales en la Cruzioseptina CC-16 (CZS-16) extraída del exudado de la rana Cruziohyla calcarifer para determinar sus propiedades fisicoquímicas y su estructura secundaria, además de realizar el acoplamiento molecular del péptido con moléculas presentes en la membrana celular bacteriana y varias enzimas cruciales para la vida de microorganismos como Escherichia coli, Staphylococcus aureus y Candida albicans.

\section{MATERIALES Y MÉTODOS}

En el presente trabajo se utilizó una variedad de recursos como servidores en línea, bases de datos, herramientas web, sistemas de visualización molecular y programas para simulaciones, cálculos y predicciones computacionales.
La predicción de las propiedades fisicoquímicas se realizó utilizando las herramientas web BioSyn (Bio-Synthesis, 2010), y PepCalc (Innovagen $A B, 2015)$ mientras que la predicción de la estructura secundaria se llevó a cabo mediante las herramientas web Predict Protein (Yachdav \& Rost, 
2013), JPred 4 (Drozdetskiy et al., 2015) y BioSyn (Bio-Synthesis, 2010). La estructura secundaria en tres dimensiones de CZS-16 fue modelada con base en las predicciones usando el programa PyMol (Schrödinger, 2017). Todas las estructuras resultantes, incluyendo las moléculas presentes en la membrana celular bacteriana, fueron optimizadas mediante el método híbrido ONIOM en dos niveles, HF/3-21G/ y HF/6-31G, ambos integrados en el programa Gaussian 09 (Frisch et al., 2009).

Para obtener más información acerca del mecanismo de acción de CZS-16 se escogieron dos blancos biológicos por cada patógeno estudiado. Sus estructuras tridimensionales fueron obtenidas de la biblioteca web RCSB Protein Data Bank (Berman et al., 2002). Posteriormente, los cálculos del acoplamiento molecular del péptido con los blancos biológicos y las moléculas presentes en la membrana celular bacteriana fueron preparados utilizando el programa AutoDock Tools (Morris et al., 2009), para finalmente realizar los cálculos en el programa AutoDock VINA (Trott \& Olson, 2010) utilizando un espaciado de $1 \mathrm{~A}$, la exhaustividad 8 y flexibilidad total de la cadena del ligando.

\section{RESULTADOS}

Previos estudios han demostrado la actividad antimicrobiana de las Cruzioseptinas frente a diferentes agentes patógenos (Proaño-Bolaños, 2016). La Cruzioseptina CC-16 pertenece a esta familia de péptidos por lo que se llevó a cabo su estudio bajo diferentes técnicas computacionales.

\section{Tabla 1. Propiedades fisicoquímicas de la CZS-16}

\begin{tabular}{cc}
\hline Parámetro & Cruzioseptina CC-16 \\
\hline Secuencia & GFLDVLKGVGAALGAVTHLINQ-NH \\
\hline Longitud & 23 \\
\hline Peso molecular & 2320,92 \\
\hline Punto isoeléctrico & 10,73 \\
\hline Formula & $\mathrm{C}_{106} \mathrm{H}_{178} \mathrm{~N}_{30} \mathrm{O}_{28}$ \\
\hline \# de átomos & 342 \\
\hline aa de carga negativa & 1 \\
\hline aa de carga positiva & 3 \\
\hline Carga & +3 (básica) \\
\hline Carga neta a pH 7 & $+3,1$ \\
\hline \% de aa neutrales & 30,43 \\
\hline \% de aa básicos & 13,04 \\
\hline \% de aa ácidos & 4,35 \\
\hline \% de aa hidrofóbicos & 52,17 \\
\hline aa=aminoácidos &
\end{tabular}


La predicción de las propiedades fisicoquímicas se muestra en la Tabla 1 , donde se presentan la secuencia de aminoácidos y la longitud, parámetros importantes, puesto que son útiles para la determinación de la estructura secundaria. Se puede observar que el péptido posee 3 aminoácidos de carga positiva y 1 de carga negativa además de una carga de +3 de carácter básica, lo cual se atribuye a su porcentaje mayoritario de aminoácidos básicos y a la amidación del C-terminal la cual aporta una carga positiva extra, también se observa que el péptido tiene una carga neta a $\mathrm{pH}$ neutro de $+3,1$. De igual manera se aprecia que este se encuentra principalmente constituidos por aminoácidos de carácter hidrofóbico.

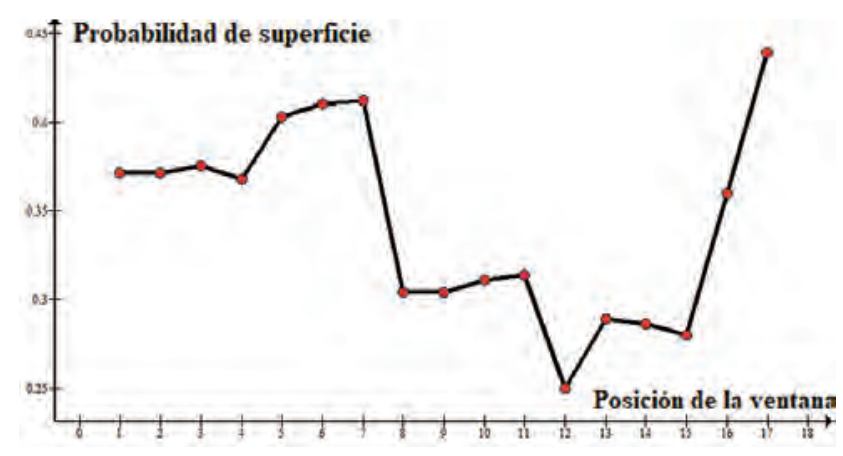

\section{Figura 1. Probabilidad de superficie del péptido de acuerdo con su secuen- cia de aminoácidos}

En la Figura 1 se puede apreciar las regiones de la secuencia que tiene mayor o menor probabilidad de que se encuentren en la superficie del péptido, donde un valor de 1,0 (que nunca ocurrirá), significaría que la re- gión contenida en la ventana centrada alrededor de ese punto está definitivamente expuesta en la superficie de la proteína y un valor de 0,0 (que tampoco ocurrirá nunca), significa que la región contenida en la 
ventana centrada alrededor de ese punto definitivamente está enterrada en el interior de la proteína. La Figura 1 muestra que las posiciones 7 y 17 de la ventana son las que tienen mayor probabilidad de estar en la superficie, pudiendo ser las más propensas a interacciones con otras moléculas.

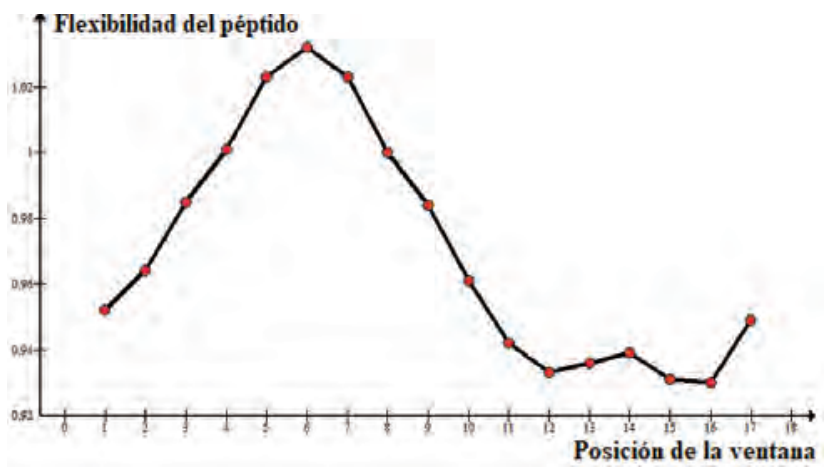

Figura 2. Flexibilidad del péptido de acuerdo con su secuencia de aminoácidos

La flexibilidad del péptido fue estudiada con el fin de determinar si esta es lo suficientemente flexible para interactuar de manera óptima con otras moléculas. Dentro de la Figura 2 se observa que la flexibilidad media del péptido es 1,0 donde se predice que regiones mayores a 1,0 son más flexibles mientras que regiones menores a 1,0 son menos flexibles, en comparación con la flexibilidad media del péptido. Se puede apreciar que la posición 6 de la ventana es la que mayor flexibilidad presenta. 
a.

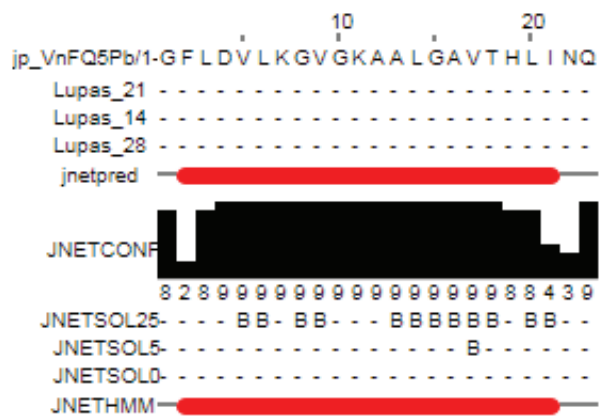

b.

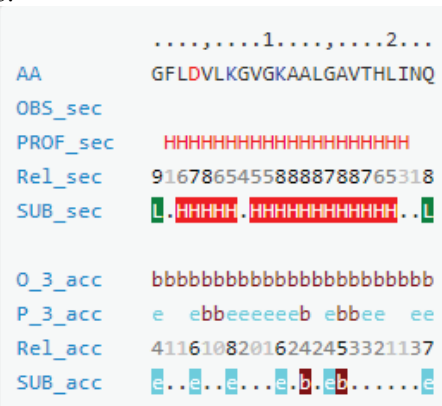

Figura 3. Estructura secundaria de CZS-16. a. Predicción obtenida por JPred 4. b. Predicción obtenida por Predictprotein

Las predicciones de la estructura secundaria de la CZS-16 muestran una conformación mayoritaria alfa-helicoidal con colas randómicas. Tanto la predicción hecha con JPred 4 como con Predictprotein muestran una conformación con un alto nivel de conservación de las propiedades químicas de los aminoácidos, esto se puede observar dentro de la Figura 3 inciso a. y b. donde el color rojo intenso es un indicador de esta característica.

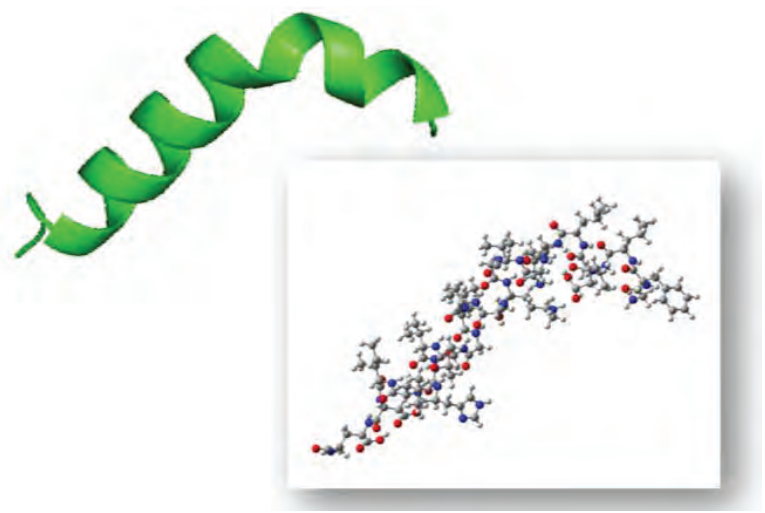

Figura 4. Estructura optimizada obłenida por el método químico cuántico ONIOM HF/6-31G 
Por otro lado, la Figura 4 muestra que la estructura optimizada presenta una gran relación con las predicciones re- alizadas ya que mantiene una estructura alfa helicoidal.

Tabla 2. Valores de afinidad entre la CZS-16 y las diferentes enzimas comparadas con sus inhibidores conocidos

\begin{tabular}{|c|c|c|c|c|}
\hline \multirow[b]{2}{*}{ Organismo } & \multirow[b]{2}{*}{ Enzima } & \multirow[b]{2}{*}{$\begin{array}{l}\text { Inhibidor } \\
\text { conocido }\end{array}$} & \multicolumn{2}{|c|}{ Afinidad (kcal/mol) } \\
\hline & & & $\begin{array}{l}\text { Afinidad con el inhibidor } \\
\text { conocido }(\mathrm{kcal} / \mathrm{mol})\end{array}$ & CZS-16 \\
\hline \multirow[t]{2}{*}{ S. aureus } & $\begin{array}{l}\text { Proteína de unión } \\
\text { de Penicilina G-acil 2A } \\
\text { (PDB:1MWT) }\end{array}$ & Ceftobiprole & $-9,5$ & $-6,0$ \\
\hline & $\begin{array}{l}\text { Hidrolasa AmiA, } \\
\text { (PDB:4KNL) }\end{array}$ & $\begin{array}{l}\text { Muramil } \\
\text { etapéptido }\end{array}$ & $-7,1$ & $-5,4$ \\
\hline \multirow[b]{2}{*}{ E. coli } & $\begin{array}{l}\text { ADN Girasa B } \\
\text { (PDB:4PRV) }\end{array}$ & ADP & $-10,4$ & $-6,1$ \\
\hline & $\begin{array}{l}\text { Proteína deunión } \\
\text { de Penicilina } \\
\text { tranglicosilasa IB } \\
\text { (PDB:3VMA) }\end{array}$ & Moenomicina & $-7,3$ & $-6,0$ \\
\hline \multirow{2}{*}{$\begin{array}{c}\text { C. } \\
\text { albicans }\end{array}$} & $\begin{array}{l}\text { Exo-B- }(1,3) \\
\text {-glucanasa } \\
\text { (PDB:1EQC) }\end{array}$ & Castanospermina & $-7,0$ & $-5,2$ \\
\hline & $\begin{array}{l}\text { Proteasa aspártica } \\
\text { secretada } \\
\text { (PDB:1EAG) }\end{array}$ & A70* & $-7,7$ & $-6,1$ \\
\hline
\end{tabular}

*A70: N-etil-N-[(4-metilpiperazin-1-yl)carbonil]-D-fenilalanil-N-[(1S,2S,4R)-4-(butilcarbamoil)-1-(ciclohexilmetil)-2hidroxi-5-metilhexil]-L-norleucinamida

Los resultados de los cálculos de acoplamiento molecular de la Cruzioseptina CC-16 con diferentes enzimas se muestra dentro de la Tabla 2. En estos estudios se observa que el péptido estudiado no muestra, en ninguno de los casos, una mayor afinidad con la enzima, en comparación con su inhibidor conocido.
Los cálculos de acoplamiento molecular también se realizaron con moléculas presentes en la membrana celular. Estos resultados se presentan en la Tabla 3. Aquí se puede observar que los valores de afinidad oscilan entre $-2,6$ y $-4,3 \mathrm{kcal} / \mathrm{mol}$ a excepción del valor de afinidad obtenido con la cardiolipina, que presenta un 
valor de $72,3 \mathrm{kcal} / \mathrm{mol}$, teniendo la menor afinidad.

\section{Tabla 3. Valores de acoplamiento de la interacción entre la CZS-16 y las moléculas presentes en la membrana celular}

\begin{tabular}{lc}
\hline $\begin{array}{l}\text { Moléculas de la } \\
\text { membrana celular }\end{array}$ & $\begin{array}{c}\text { Afinidad } \\
\text { (kcal/mol) }\end{array}$ \\
\cline { 2 - 2 } CZS-16 \\
\hline Ácido Teicoico & $-3,2$ \\
\hline beta 1-3 glucano & $-3,1$ \\
\hline Cardiolipina & 72,3 \\
\hline Fosfatidiletanolamina & $-3,0$ \\
\hline Glicofosfolípidos & $-4,3$ \\
\hline Fosfoaminolípido & $-3,6$ \\
\hline Glicofosfolipido GPLs & $-3,1$ \\
\hline Lisil-Fosfatidilglicerol & $-3,1$ \\
\hline Ácido mirístico & $-2,8$ \\
\hline Ácido oleico & $-2,8$ \\
\hline Ácido palmítico & $-3,2$ \\
\hline Ácido palmitoleico & $-2,6$ \\
\hline Fosfatidilglicerol &
\end{tabular}

\section{DISCUSIÓN}

La predicción de las propiedades fisicoquímicas de la CZS-16 (Tabla 1) muestran que el péptido posee una cadena corta de 23 aminoácidos, donde sobresale la presencia de aminoácidos de carga positiva y de características básicas como la lisina y la histidina, conformando el 13,04\% del total de los residuos, y tan solo un aminoácido de carga negativa y características acidas, el ácido aspár- tico, lo que representa el 4,35\% del total de residuos del péptido. La predominancia de los aminoácidos de carga positiva es lo que le atribuye a la CZS-16 su carga y punto isoeléctrico. El 30,43 \% de aminoácidos neutrales le confiere al péptido grupos funcionales polares con capacidad de formar puentes de hidrógeno, mientras que el 52,17 \% de aminoácidos hidrofóbicos otorgan estabili- 
dad a la estructura, tendiendo a ubicarse en la zona central de la molécula al plegarse la estructura (Caltabiano et al., 2013; Hughes, 2013).

Los péptidos catiónicos son conocidos por tener una alta actividad frente a bacterias tanto Gram positivas como Gram negativas. Estos péptidos están definidos como cadenas de entre 15 y 30 residuos de largo, con una carga neta positiva atribuida a un exceso de aminoácidos básicos, además de poseer más del $50 \%$ de su estructura conformada por aminoácidos hidrofóbicos (Lamont et al., 2015; Vishnepolsky \& Pirtskhalava, 2014). Al contrastar los resultados de la predicción de las propiedades fisicoquímicas de la CZS-16 con la información expuesta, se puede afirmar que este péptido puede ser catalogado como un péptido catiónico.

La probabilidad de superficie muestra que la posición de las ventanas 7 y 17 son las que se encuentran más expuestas en la superficie del péptido (Figura 1), comprendiendo a cada posición de la ventana como una región contenida de 6 aminoácidos. La posición 7 contiene los residuos
KGVGKA (lisina, glicina, valina, glicina, lisina, alanina) y la posición 17 contiene los residuos VTHLIN (valina, treonina, histidina, leucina, isoleucina, asparagina). Se puede apreciar que ambas regiones se encuentran compuestas por aminoácidos básicos con carga positiva, rodeados por aminoácidos neutrales e hidrofóbicos, por lo que se puede presumir que estas zonas acumularán un potencial positivo siendo focos para interacciones electrostáticas (Celis et al., 2005; Soreq, 2012).

La flexibilidad de los péptidos determina la capacidad de estos para sufrir cambios conformacionales, lo cual es crucial al momento de interactuar con diferentes moléculas como proteínas, enzimas o la misma membrana bacteriana (Craveur et al., 2015; Fieser et al., 1987). La Figura 2 muestra las posibles regiones rígidas y flexibles que posee la CZS-16, siendo flexibles las comprendidas entre la posición de ventanas 4 y 8 , con la posición 6 como las más flexible. El resto de las posiciones son regiones rígidas, con la posición 16 como la más rígida. La posición 6 comprende a la sección de la cadena LKGVGK (leucina, lisina, glicina, valina, glicina, lisina), la cual está con- 
formada por aminoácidos básicos con carga positiva, rodeados por aminoácidos neutrales e hidrofóbicos, mientras que la posición 16 comprende a la sección de la cadena AVTHLI (alanina, valina, treonina, histidina, leucina, isoleucina), compuesta por un aminoácido básico de carga positiva rodeado por aminoácidos hidrofóbicos.

Se aprecia que para la CZS-16 se tiene una tendencia a ser más flexible en las secciones centrales, lo cual es contradictorio, pues para este tipo de moléculas es común que las regiones extremas sean más flexibles. Al contrastar los resultados de flexibilidad con la predicción de la estructura secundaria se puede apreciar una contracción similar, puesto que la sección de la cadena correspondiente a la posición 6 presenta una conformación alfa helicoidal, que es menos flexible que la conformación de cola randómica presente en las zonas extremas, debido a la formación de puentes de hidrogeno entre aminoácidos (Jacobs et al., 2001; Lexa \& Carlson, 2012). Aun así, se puede apreciar que en la estructura optimizada existe una ligera curvatura en la zona correspondiente a la posición 6 (Figura 5). Por tanto, es necesario un estudio más detallado mediante técnicas de dinámica molecular, para poder descartar o corroborar la predicción de la flexibilidad del péptido.

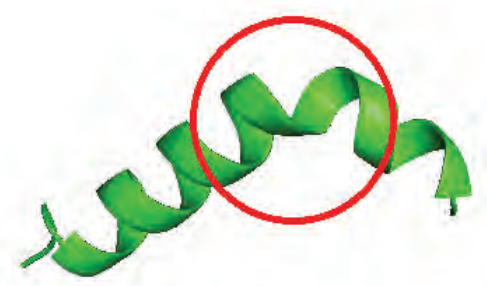

Figura 5. Sección correspondiente a la posición de ventana predicha como más flexible en la CZS-16

Las predicciones de la estructura secundaria de la CZS-16 coinciden en que el péptido adopta de forma mayoritaria una conformación alfa helicoidal (Figura 3), siendo en ambos casos el 86,96 \% de la composición total, variando únicamente en las zonas extremas donde el primer (glicina) y los dos últimos residuos (asparagina y glutamina) no adoptarán esta conformación. La predominancia de la estructura alfa helicoidal se puede dar por la amplia presencia de aminoácidos neutrales e hidrofóbicos, ya que estos tienden a formar puentes de hidrógeno entre sí, dando origen a esta conformación (Meng \& Kurgan, 2016). 
La estructura optimizada muestra una gran similitud con las predicciones, pues aún presenta una predominancia de la conformación alfa helicoidal, variando únicamente en la desestabilización de la estructura helicoidal de dos residuos, la fenilalanina y la isoleucina, los cuales se presentan como cola randómica en la estructura optimizada, extendiendo ligeramente esta conformación en los extremos en comparación con las predicciones.

Los mecanismos de acción de los AMPs pueden ser divididos en dos grupos, modulación inmunológica y muerte directa. Los mecanismos de muerte directa son mucho más comunes en los AMPs de carácter catiónico y pueden ser de dos tipos, ataque concentrado en la membrana o no concentrado en la membrana (Kumar et al., 2018; Vishnepolsky \& Pirtskhalava, 2014). Los estudios de acoplamiento molecular de la CZS16 con diferentes enzimas, cumplen la función de determinar si el péptido podría actuar mediante un mecanismo de ataque no concentrado en la membrana por inhibición enzimática, mientras que los estudios de acoplamiento molecular de la CZS-
16 con diferentes moléculas presentes en la membrana celular bacteriana arrojan información sobre la interacción individual del péptido con componentes de la membrana para determinar un posible mecanismo de acción mediante un ataque concentrado en la membrana.

En el caso del acoplamiento de la CZS-16 con la proteína de unión de Penicilina G-acil 2a, el péptido no podrá inhibir la enzima debido a su gran tamaño, puesto que éste se encuentra conformado por 342 átomos a diferencia de su inhibidor, el Ceftobiprole, con 58 átomos, por lo que no podrá ingresar de manera eficiente al bolsillo enzimático, además de que existe una diferencia de cargas a $\mathrm{pH}$ fisiológico siendo de -1 para el inhibidor y de $+3,1$ para el péptido. Algo similar sucede con la Hidrolasa AmiA donde su inhibidor, el Muramil tetrapéptido, posee apenas 4 aminoácidos mientras que la CZS16 posee 23, siendo demasiado grande para interactuar con el bolsiIlo enzimático.

En el caso de la ADN Girasa B se puede apreciar que el valor de afinidad del péptido es particularmente 
bajo en comparación con el inhibidor conocido, lo cual se puede dar debido a la diferencia de tamaños y cargas entre estos. Aun así, en de la Figura 6 se puede apreciar una interacción profunda de la lisina 11 (Lys 11) del péptido con el sitio activo de la enzima, esto debido a que el sustituyente amino positivamente cargado de la Lys 11 se encuentra particularmente expuesto facilitando así la interacción electrostática con el sitio activo negativamente cargado.

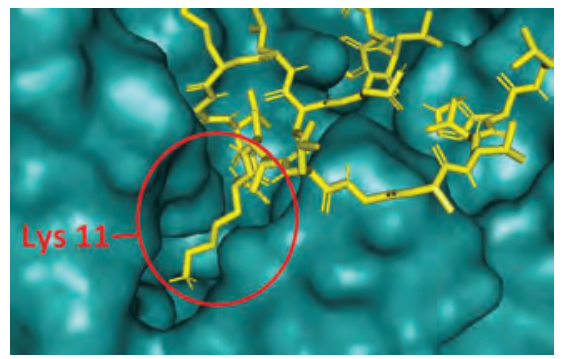

Figura 6. Interacción de la ADN Girasa B (azul) con la CZS-16 (amarillo)

El acoplamiento con la proteína de unión de Penicilina transglicosilasa 1B muestra buena proximidad entre los valores de afinidad del inhibidor y el péptido, debido a que la enzima posee buena exposición del bolsillo enzimático, dando paso a interacciones electrostáticas o hidrofóbicas (Figura 7).

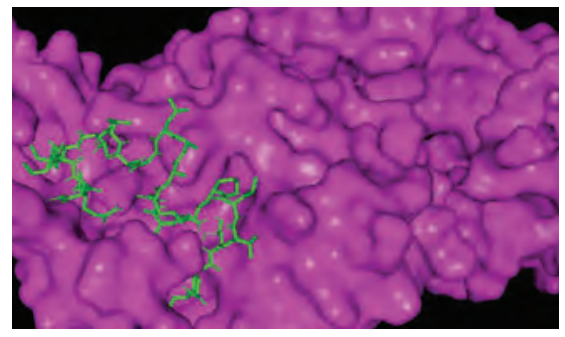

Figura 7. Interacción de la proteína de unión de Penicilina transglicosilasa 1B (magenta) con la CZS-16 (verde)

El acoplamiento con la enzima ExoB-(1,3)-glucanasa muestra que el péptido no puede interactuar de manera directa con el sitio activo de la enzima, mientras tanto, debido al tamaño relativamente pequeño de la enzima y al gran tamaño del péptido se puede dar que éste recubra el sitio activo, impidiendo la entrada del sustrato (Figura 8). La Exo-B-(1,3)-glucanasa tiene como función el proveer de energía a la célula mediante la hidrolisis de glucanos, por lo que al impedir la entrada del sustrato se impide el suministro de energía, causando la muerte de la célula fúngica. 


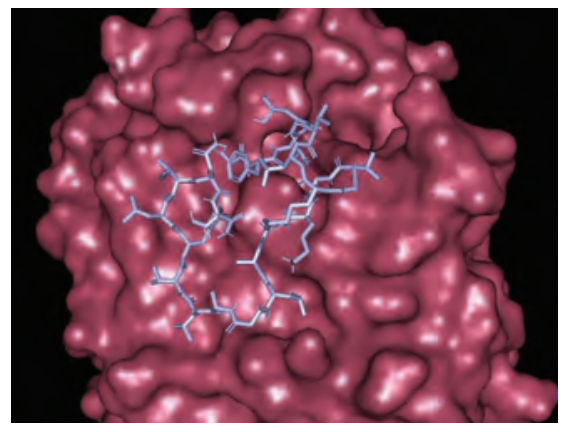

Figura 8. Interacción de la Exo-B-(1,3)glucanasa (rojo) con la CZS-16 (azul)

Por otro lado, la Proteasa aspártica secretada, es una enzima que rompe los enlaces peptídicos de moléculas como proteínas o péptidos. Con base en esto, se puede establecer que la CZS-16 no podría ser usada como inhibidor, puesto que esta se hidrolizaría siendo el sustrato mismo de la enzima.

Los estudios de acoplamiento de la CZS-16 con diferentes moléculas presentes en la membrana celular bacteriana arrojan puntajes de afinidad que van desde $-2,6$ hasta $-4,3$ $\mathrm{kcal} / \mathrm{mol}$, excluyendo a la cardiolipina que presentó un valor de afinidad de $72,3 \mathrm{kcal} / \mathrm{mol}$. Este puntaje muestra que existe una interacción nula entre esta molécula y la CZS-16, debido a que la cardiolipina es parti- cularmente voluminosa ya que posee largas cadenas carbonadas que dificultan la interacción con péptidos básicos (Cuesta et al., 2019).

La monocapa externa de la bicapa lipídica en la membrana bacteriana está formada principalmente por lípidos con grupos cargados negativamente con los que los AMPs catiónicos tienen fuertes interacciones electrostáticas (Kumar et al., 2018; Yang et al., 2018). Moléculas como los glicofosfolípidos, los fosfoaminolípidos, el fosfatidilglicerol y la fosfatidiletanolamina, que poseen fuertes cargas negativas, muestran buena interacción con la CZS-16, por lo que el péptido podría causar el pliegue de estas abriendo la membrana bacteriana externa, para un posterior ataque a la membrana interna (Bechinger \& Gorr, 2017; Kumar et al., 2018; Peters et al., 2010).

La interacción de la CZS-16 con el ácido teicoico puede causar la apertura de la pared celular bacteriana de las bacterias Gram positivas, facilitando la interacción del péptido con el lisil-fosfatidilglicerol en la membrana citoplasmática, disminuyendo las defensas de la célula ante otros 
péptidos catiónicos. Por otro lado, la interacción con el beta 1-3 glucano puede causar la perdida de elastici- dad de la membrana citoplasmática fúngica (Piotrowski et al., 2015; Swoboda et al., 2010).

\section{CONCLUSIÓN}

Los resultados de los estudios computacionales realizados sobre la Cruzioseptina CC-16 identificados en la especie de anfibio Cruziohyla calcarifer muestran que este es un péptido de 23 residuos de largo con una conformación alfa helicoidal predominante, un punto isoeléctrico de 10,73, una carga de +3 de carácter básica y una carga neta a $\mathrm{pH} 7$ de $+3,1$. Además de esto, debido a su carga neta positiva atribuida a un exceso de aminoácidos básicos y al hecho de poseer más del $50 \%$ de su estructura conformada por aminoácidos hidrofóbicos, se puede clasificar a la CZS-16 como un péptido antimicrobiano catiónico. Los estudios de acoplamiento molecular muestran que un mecanismo de acción basado en inhibición enzimática no es posible, debido principalmente al tamaño del péptido, mientras que un mecanismo con base en un ataque concentrado en la membrana microbiana puede ser viable, debido a que la CZS-16 puede causar la disrupción de la membrana mediante la interacción electrostáticas entre los residuos con carga positiva y los componentes de la membrana, como glicofosfolípidos, fosfoaminolípidos, fosfolípidos, etc. con carga negativa, siendo este el mecanismo de acción más común entre los AMPs catiónicos según la bibliografía.

\section{AGRADECIMIENTOS}

Este trabajo tuvo financiamiento de la Pontificia Universidad Católica del
Ecuador a través del proyecto QINV0180-IINV529020200. 


\section{LISTA DE REFERENCIAS}

Bastos, M. C., Santos, D. R. dos, Aubertheau, É., Lima, J. A. M. de C., Guet, T. L., Caner, L., Mondamert, L., \& Labanowski, J. (2018). Antibiotics and microbial resistance in Brazilian soils under manure application. Land Degradation \& Development, 29(8), 2472-2484. https://doi.org/10.1002/ldr.2964

Bechinger, B., \& Gorr, S.-U. (2017). Antimicrobial Peptides: Mechanisms of Action and Resistance. Journal of Dental Research, 96(3), 254-260. https://doi.org/10.1177 /0022034516679973

Berman, H. M., Battistuz, T., Bhat, T. N., Bluhm, W. F., Bourne, P. E., Burkhardt, K., Feng, Z., Gilliland, G. L., Iype, L., Jain, S., Fagan, P., Marvin, J., Padilla, D., Ravichandran, V., Schneider, B., Thanki, N., Weissig, H., Westbrook, J. D., \& Zardecki, C. (2002). The Protein Data Bank. Acta Crystallographica. Section D, Biological Crystallography, 58(Pt 6 No 1), 899-907. https://doi.org/10.1107/s0907444902003451

Bio-Synthesis. (2010). Peptide Calculator. https://www.biosyn.com/peptidepropertycalculatorlanding.aspx

Caltabiano, G., Gonzalez, A., Cordomí, A., Campillo, M., \& Pardo, L. (2013). The role of hydrophobic amino acids in the structure and function of the rhodopsin family of G protein-coupled receptors. Methods in Enzymology, 520, 99-115. https://doi.org/10.1016/B978-0-12-391861-1.00005-8

Candido, E., de Barros, E., Cardoso, M., \& Franco, O. (2019). Bacterial cross-resistance to anti-infective compounds. Is it a real problem? Current Opinion in Pharmacology, 48, 76-81. https://doi.org/10.1016/j.coph.2019.05.004

Celis, J. E., Carter, N., Simons, K., Small, J. V., Hunter, T., \& Shotton, D. (2005). Cell Biology: A Laboratory Handbook. Elsevier.

Ciemny, M., Kurcinski, M., Kamel, K., Kolinski, A., Alam, N., Schueler-Furman, O., \& Kmiecik, S. (2018). Protein-peptide docking: Opportunities and challenges. Drug Discovery Today, 23(8), 1530-1537. https://doi.org/10.1016/j.drudis.2018.05.006 
Ciumac, D., Gong, H., Hu, X., \& Lu, J. R. (2019). Membrane targeting cationic antimicrobial peptides. Journal of Colloid and Interface Science, 537, 163-185. https://doi.org/10.1016/j.jcis.2018.10.103

Conlon, J. M., Mechkarska, M., \& Leprince, J. (2019). Peptidomic analysis in the discovery of therapeutically valuable peptides in amphibian skin secretions. Expert Review of Proteomics, 16(11-12), 897-908. https://doi.org/10.1080/ 147894 50.2019 .1693894

Craveur, P., Joseph, A. P., Esque, J., Narwani, T. J., Noël, F., Shinada, N., Goguet, M., Leonard, S., Poulain, P., Bertrand, O., Faure, G., Rebehmed, J., Ghozlane, A., Swapna, L. S., Bhaskara, R. M., Barnoud, J., Téletchéa, S., Jallu, V., Cerny, J., ... de Brevern, A. G. (2015). Protein flexibility in the light of structural alphabets. Frontiers in Molecular Biosciences, 2. https://doi.org/10.3389/fmolb.2015.00020

Cuesta, S., Arias, J., Gallegos, F., Proaño-Bolaños, C., Blasco-Zúñiga, A., Rivera, M., \& Meneses, L. (2019). Modelamiento molecular de la dermaseptina SP2 extraída de Agalychnis spurrelli. infoANALÍTICA, 7(1), 41-56. https://doi.org/10.26807/ia. v7i1.95

Cuesta, S., Gallegos, F., Arias, J., Pilaquinga, F., Blasco-Zúñiga, A., Proaño-Bolaños, C., Rivera, M., \& Meneses, L. (2019). Molecular modeling of four Dermaseptin-related peptides of the gliding tree frog Agalychnis spurrelli. Journal of Molecular Modeling, 25(9), 260. https://doi.org/10.1007/s00894-019-4141-1

Cui, D., Liu, X., Hawkey, P., Li, H., Wang, Q., Mao, Z., \& Sun, J. (2017). Use of and microbial resistance to antibiotics in China: A path to reducing antimicrobial resistance. Journal of International Medical Research, 45(6), 1768-1778. https://doi.org/10.1177/0300060516686230

Demori, I., El Rashed, Z., Corradino, V., Catalano, A., Rovegno, L., Queirolo, L., Salvidio, S., Biggi, E., Zanotti-Russo, M., Canesi, L., Catenazzi, A., \& Grasselli, E. (2019). Peptides for Skin Protection and Healing in Amphibians. Molecules, 24(2), 347. https://doi.org/10.3390/molecules24020347

Drozdetskiy, A., Cole, C., \& Procter, J. (2015). JPred4: A protein secondary structure prediction server. https://www.ncbi.nlm.nih.gov/pmc/articles/PMC4489285/ 
Fieser, T. M., Tainer, J. A., Geysen, H. M., Houghten, R. A., \& Lerner, R. A. (1987). Influence of protein flexibility and peptide conformation on reactivity of monoclonal anti-peptide antibodies with a protein alpha-helix. Proceedings of the National Academy of Sciences of the United States of America, 84(23), 8568-8572. https://doi.org/10.1073/pnas.84.23.8568

Frisch, M. J., Trucks, G. W., Schlegel, H. B., Scuseria, G. E., Robb, M. A., Cheeseman, J. R., Scalmani, G., Barone, V., \& Petersson, G. A. (2009). Gaussian 09, Revision C.01. Gaussian, Inc.

Gorr, S.-U., \& Abdolhosseini, M. (2011). Antimicrobial peptides and periodontal disease. Journal of Clinical Periodontology, 38(s11), 126-141. https://doi.org/10.1111/j. 1600-051X.2010.01664.x

Haney, E. F., Mansour, S. C., \& Hancock, R. E. W. (2017). Antimicrobial Peptides: An Introduction. En P. R. Hansen (Ed.), Antimicrobial Peptides (Vol. 1548, pp. 3-22). Springer New York. https://doi.org/10.1007/978-1-4939-6737-7_1

Hoagland, P. D., Unruh, J. J., Wickham, E. D., \& Farrell, H. M. (2001). Secondary Structure of Bovine $\alpha$ S2-Casein: Theoretical and Experimental Approaches1. Journal of Dairy Science, 84(9), 1944-1949. https://doi.org/10.3168/jds.S0022-0302(01) 74636-X

Hughes, A. (2013). Amino Acids, Peptides and Proteins in Organic Chemistry, Analysis and Function of Amino Acids and Peptides. John Wiley \& Sons.

Innovagen AB. (2015). PepCalc.com-Peptide calculator. https://pepcalc.com/

Jacobs, D. J., Rader, A. J., Kuhn, L. A., \& Thorpe, M. F. (2001). Protein flexibility predictions using graph theory. Proteins, 44(2), 150-165. https://doi.org/10.1002/prot. 1081

Kim, B. Y., \& Jin, B. R. (2019). Antimicrobial activity of the C-terminal of the major royal jelly protein 4 in a honeybee (Apis cerana). https://pubag.nal.usda.gov/catalog 16367364 
Kumar, P., Kizhakkedathu, J., \& Straus, S. (2018). Antimicrobial Peptides: Diversity, Mechanism of Action and Strategies to Improve the Activity and Biocompatibility In Vivo. Biomolecules, 8(1), 4. https://doi.org/10.3390/biom8010004

Kwon, J. Y., Kim, M. K., Mereuta, L., Seo, C. H., Luchian, T., \& Park, Y. (2019). Mechanism of action of antimicrobial peptide P5 truncations against Pseudomonas aeruginosa and Staphylococcus aureus. AMB Express, 9. https://doi.org/10.1186/s13568-0190843-0

Lamont, R. J., Hajishengallis, G. N., \& Jenkinson, H. F. (2015). Microbiología e inmunología oral. Editorial El Manual Moderno.

Latendorf, T., Gerstel, U., Wu, Z., Bartels, J., Becker, A., Tholey, A., \& Schröder, J.-M. (2019). Cationic Intrinsically Disordered Antimicrobial Peptides (CIDAMPs) Represent a New Paradigm of Innate Defense with a Potential for Novel Anti-Infectives. Scientific Reports, 9(1), 3331. https://doi.org/10.1038/s41598-019-39219-w

Lewin, A. C., Hausmann, J. C., \& Miller, P. E. (2017). Intraocular pressure and examination findings in three species of central and south american tree frogs (Cruziohyla craspedopus, Cruziohyla calcarifer, and Anotheca spinosa). Journal of Zoo and Wildlife Medicine: Official Publication of the American Association of Zoo Veterinarians, 48(3), 688-693. https://doi.org/10.1638/2016-0243.1

Lexa, K. W., \& Carlson, H. A. (2012). Protein Flexibility in Docking and Surface Mapping. Quarterly reviews of biophysics, 45(3), 301-343. https://doi.org/10.1017/S0033 583512000066

Li, J., Koh, J.-J., Liu, S., Lakshminarayanan, R., Verma, C. S., \& Beuerman, R. W. (2017). Membrane Active Antimicrobial Peptides: Translating Mechanistic Insights to Design. Frontiers in Neuroscience, 11. https://doi.org/10.3389/fnins.2017.00073

Martinez, J. L. (2014). General principles of antibiotic resistance in bacteria. Drug Discovery Today: Technologies, 11, 33-39. https://doi.org/10.1016/j.ddtec.2014.02. 001

Meng, F., \& Kurgan, L. (2016). Computational Prediction of Protein Secondary Structure from Sequence. Current Protocols in Protein Science, 86(1), 2.3.1-2.3.10. https://doi.org/10.1002/cpps.19 
Mingqiang, R., Jie, L., Qiong, L., Zhilong, L., Bo, W., Yan, R., \& Ren, L. (2018). The defensive system of tree frog skin identified by peptidomics and RNA sequencing analysis. Amino Acids, 51(2), 345-353. https://doi.org/10.1007/s00726-018-2670-z

Morris, G. M., Huey, R., Lindstrom, W., Sanner, M. F., Belew, R. K., Goodsell, D. S., \& Olson, A. J. (2009). AutoDock4 and AutoDockTools4: Automated docking with selective receptor flexibility. Journal of Computational Chemistry, 30(16), 27852791. https://doi.org/10.1002/jcc.21256

Nikolaieva, I., Yu, D., Oliinyk, D., Oskyrko, O., Marushchak, O., Halenova, T., \& Savchuk, O. (2018). Amphibian skin secretions: A potential source of proteolytic enzymes. Biotechnologia Acta, 11(5), Article 5. https://cyberleninka.ru/article/n/ amphibian-skin-secretions-a-potential-source-of-proteolytic-enzymes

Peters, B. M., Shirtliff, M. E., \& Jabra-Rizk, M. A. (2010). Antimicrobial Peptides: Primeval Molecules or Future Drugs? PLoS Pathogens, 6(10), e1001067. https://doi.org /10.1371/journal.ppat.1001067

Piotrowski, J. S., Okada, H., Lu, F., Li, S. C., Hinchman, L., Ranjan, A., Smith, D. L., Higbee, A. J., Ulbrich, A., Coon, J. J., Deshpande, R., Bukhman, Y. V., Mcllwain, S., Ong, I. M., Myers, C. L., Boone, C., Landick, R., Ralph, J., Kabbage, M., \& Ohya, Y. (2015). Plant-derived antifungal agent poacic acid targets $\square-1,3$-glucan. Proceedings of the National Academy of Sciences, 112(12), E1490-E1497. https://doi.org /10.1073/pnas.1410400112

Proaño-Bolaños, C. (2016). Peptidomic approach identifies cruzioseptins, a new family of potent antimicrobial peptides in the splendid leaf frog, Cruziohyla calcarifer. Journal of Proteomics, 13.

Proaño-Bolaños, C., Blasco-Zúñiga, A., De Almeida, J., Wang, L., Llumiquinga, M., Rivera, M., Zhou, M., Chen, T., \& Shaw, C. (2019). Unravelling the Skin Secretion Peptides of the Gliding Leaf Frog, Agalychnis spurrelli (Hylidae). Biomolecules, 9, 1-20. https://doi.org/10.3390/biom9110667

Rhouma, M., Beaudry, F., Thériault, W., \& Letellier, A. (2016). Colistin in Pig Production: Chemistry, Mechanism of Antibacterial Action, Microbial Resistance Emergence, and One Health Perspectives. Frontiers in Microbiology, 7. https://doi.org/10. 3389/fmicb.2016.01789 
Roca, I., Akova, M., Baquero, F., Carlet, J., Cavaleri, M., Coenen, S., Cohen, J., Findlay, D., Gyssens, I., Heure, O. E., Kahlmeter, G., Kruse, H., Laxminarayan, R., Liébana, E., López-Cerero, L., MacGowan, A., Martins, M., Rodríguez-Baño, J., Rolain, J.M., ... Vila, J. (2015). The global threat of antimicrobial resistance: Science for intervention. New Microbes and New Infections, 6, 22-29. https://doi.org/10. 1016/j.nmni.2015.02.007

Rudi, J. M., Müller, D. M., Siano, A., Simonetta, A. C., \& Tonarelli, G. G. (2010). Péptido Antimicrobiano Quimérico de Dermaseptina-S1 y Tigerinina-1: Estructura Secundaria y Selectividad hacia Membranas. FABICIB, 14, 148-161. https://doi.org/10. 14409/fabicib.v14i1.859

Rydberg, H. A., Carlsson, N., \& Nordén, B. (2012). Membrane interaction and secondary structure of de novo designed arginine-and tryptophan peptides with dual function. Biochemical and Biophysical Research Communications, 427(2), 261-265. https://doi.org/10.1016/j.bbrc.2012.09.030

Schrödinger. (2017). The PyMOL Molecular Graphics System (Versión 2.0) [Python]. Schrödinger, LLC.

Soreq, H. (2012). Human Cholinesterases and Anticholinesterases. Academic Press.

Swoboda, J. G., Campbell, J., Meredith, T. C., \& Walker, S. (2010). Wall Teichoic Acid Function, Biosynthesis, and Inhibition. ChemBioChem, 11(1), 35-45. https://doi. org/10.1002/cbic.200900557

Trott, O., \& Olson, A. J. (2010). AutoDock Vina: Improving the speed and accuracy of docking with a new scoring function, efficient optimization, and multithreading. Journal of Computational Chemistry, 31(2), 455-461. https://doi.org/10.1002 /jcc. 21334

Vishnepolsky, B., \& Pirtskhalava, M. (2014). Prediction of linear cationic antimicrobial peptides based on characteristics responsible for their interaction with the membranes. Journal of Chemical Information and Modeling, 54(5), 1512-1523. https://doi.org/10.1021/ci4007003 
Walsh, C. T., \& Wencewicz, T. A. (2014). Prospects for new antibiotics: A molecule-centered perspective. The Journal of Antibiotics, 67(1), 7-22. https://doi.org/10.1038 /ja.2013.49

Yachdav, G., \& Rost, B. (2013). PredictProtein-Protein Sequence Analysis, Prediction of Structural and Functional Features. https://predictprotein.org/

Yang, M., Zhang, C., Zhang, M. Z., \& Zhang, S. (2018). Beta-defensin derived cationic antimicrobial peptides with potent killing activity against gram negative and gram positive bacteria. BMC Microbiology, 18(1), 54. https://doi.org/10.1186/s12866018-1190-z

Yasir, M., Dutta, D., \& Willcox, M. D. P. (2019). Comparative mode of action of the antimicrobial peptide melimine and its derivative Mel4 against Pseudomonas aeruginosa. Scientific Reports, 9(1), 7063. https://doi.org/10.1038/s41598-019-42440-2 